\title{
STOCHASTIC SIMULATION OF OPTIMAL INSURANCE POLICIES TO MANAGE SUPPLY CHAIN RISK
}

\author{
Elliot M. Wolf \\ Syngenta Crop Protection, LLC \\ Greensboro, NC 27409, USA
}

\begin{abstract}
Manufacturing firms, particularly those in the chemical industry, typically employ risk management principles to identify, analyze, and prioritize risks that have the potential to cause significant property damage and business interruption to operating assets. These risks, which may exceed the firm's financial capacity post-loss, can be hedged using financial instruments in the insurance markets. Many firms design insurance programs to share the loss exposure; however characterization of the loss distributions and determination of the optimal coverage limits is more challenging.

Few applied simulation models have been published in the open literature to address optimal insurance policies, despite the importance and value provided to shareholders. Consequently, corporate risk managers often rely on heuristics or past decisions to structure insurance programs during renewal periods. This simulation model considers the benefit of risk management given loss distributions specific to contract manufacturers and establishes a scientific approach for making optimal insurance policy decisions.
\end{abstract}

\section{INTRODUCTION}

Since the 1960s, corporations have learned from adverse financial events and have evolved to a more integrated framework of risk management. Enterprise risk management (ERM) is a coordinated and strategic effort to view all risks faced by the firm together. ERM applies processes to identify risks and manage loss through investment, insurance or other financial instruments via retention, reduction, transfer, or avoidance. Insurance is one mechanism to transfer the risk of adverse unpredictable events to a third party and markets are available to provide indemnity for property damage, business interruption, and contingent business interruption (CBI). Property damage insurance covers unforeseen physical loss or damage associated with plant or equipment. Business interruption insurance is designed to protect the earnings of a business where coverage is triggered by damage from a covered cause of loss to covered property that causes a necessary suspension of business operations. CBI insurance reimburses a company for lost profits due to an insurable loss suffered by one or more of its suppliers or customers. CBI insurance is triggered if there is a direct physical loss or damage to a dependent property (supplier or customer), the loss is caused by a covered cause of loss, and the loss results in a suspension of operations at a covered location.

The purpose of this research is to consider the cost of risk due to the non-linearity in the tax code for a firm utilizing contract manufacturers (i.e., tollers) within the supply chain and how CBI insurance can be used to hedge this risk. In the model, tollers are utilized in the supply chain downstream of manufacturing plants to complete the processing steps necessary to produce the finished goods. Thus, although CBI 
insurance typically involves upstream suppliers, in this model the insurance applies to a downstream toller operation between the plant and the customer.

Before discussing the insights from the model, it is prudent to review how risk reduction adds value to shareholders. The well-known Miller-Modigliani (1958) hypothesis suggests that in a perfect capital market the method that the firm uses to finance losses does not affect firm value. A firm may choose between issuing new equity capital, new debt capital, internal funds, or insurance indemnity payments (Harrington, Niehaus, and Risko 2002). However, it is clear in theory that regardless of the form of financing, the value of risk reduction must be found in the capital market inefficiencies. It makes sense to only reduce the cash flow variability of risks that present a "real" cost to the firm (Stultz 1996). The academic finance literature has identified three major costs associated with higher earnings variability: 1) higher expected bankruptcy costs, 2) higher expected payments to corporate "stakeholders", and 3) higher expected tax payments (Stultz 1996).

Addressing the first, risk management can reduce bankruptcy costs by reducing the probability of default which in turn would trigger legal costs, court costs, and threaten longer term viability of ongoing operating value derived from the assets. In addition, firms perceived as a credit risk due to default probability may become more difficult to raise funds for investment projects. Passing up investment opportunities, the so-called under-investment problem, is an important financial distress cost. To the extent that risk management can reduce the probability of default, then this represents an increase in firm value through cost avoidance.

Second, risk management can reduce costs associated with shareholder payments. Employees will demand higher wages when exposed to greater operational risks or when the probability of layoff is greater. Managers with alternative employment options will require higher salaries to remain with firms where the risk of financial insolvency is high.

Third, risk management can reduce tax payments as a result of the convexity of the tax code. In the U.S., tax shields such as depreciation represent an earnings threshold below which earnings are tax free. Above the threshold, earnings are taxed at a marginal rate. Therefore, reducing earnings volatility maximizes the benefit of realizing the full potential of the tax benefit each period. Thus, losses that can be insured represent an opportunity for increasing earnings or alternatively, equivalent earnings at reduced risk.

Figure 1 illustrates the interesting relationship between risk and expected tax liability. This example draws heavily upon that of Doherty (2000). Given the progressivity of the tax code, suppose that earnings by the firm are "tax free" below a given tax shield (depreciation) and taxed at a marginal rate above this amount as shown by the tax function. Suppose one firm has expected earnings of C. If the firm earns exactly $C$, then the tax can be read directly off the schedule as $T(C)$. Suppose another firm has equal chances of earning $\mathrm{A}$ and $\mathrm{B}$. There is a $50 \%$ chance of earning $\mathrm{A}$ and a $50 \%$ chance of earning $\mathrm{B}$. If the firm earns $A$, then taxes are zero since it is below the tax shield. If the firm earns B, then taxes are due at the marginal rate less depreciation. Notice that the expected tax of the first firm is considerably less than the second firm despite the fact that the expected earnings are the same. 


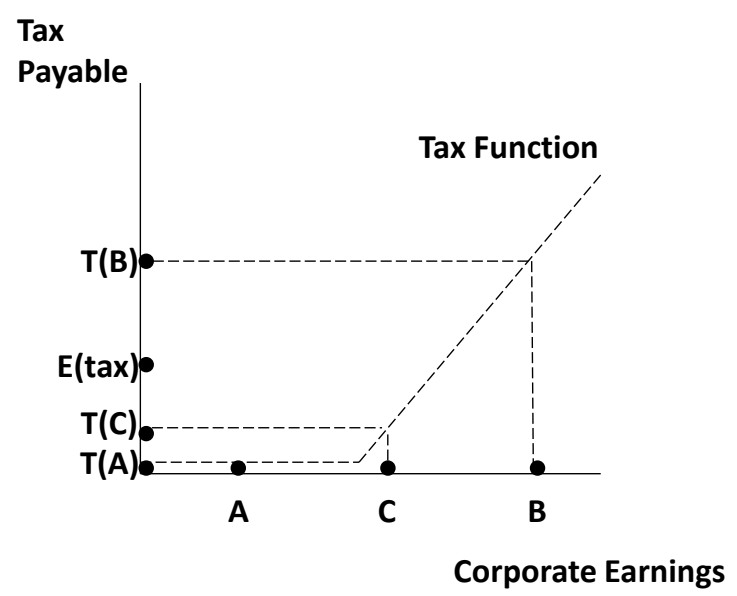

Figure 1: Risk and tax effects

This tax advantage can be understood in terms of risk management. Even though this is a simple illustration, whereas, in reality losses may be carried forward to future tax periods the principle remains the same. Firms that can hedge losses reduce the riskiness of earnings which has a general tax benefit.

There are other reasons to hedge and a summary is provided in Table 1 as outlined by Doherty (2000). Generally speaking, firms that exhibit high leverage, high growth, high R\&D investment, or a ratio of tax shield-to-earnings near one are most likely to benefit from hedging strategies.

Table 1: Firms most likely to hedge.

\begin{tabular}{|l|l|}
\hline Tax Nonlinearity & $\begin{array}{l}\text { Ratio }- \text { Tax Shield: } \\
\text { Earnings } \approx 1\end{array}$ \\
\hline $\begin{array}{l}\text { Financial Distress - } \\
\text { Direct }\end{array}$ & High leverage \\
\hline $\begin{array}{l}\text { Financial Distress - } \\
\text { Indirect }\end{array}$ & $\begin{array}{l}\text { High leverage } \\
\text { High growth } \\
\text { High R\&D }\end{array}$ \\
\hline Crowding out & $\begin{array}{l}\text { High leverage } \\
\text { High growth } \\
\text { High R\&D }\end{array}$ \\
\hline $\begin{array}{l}\text { Managerial Utility } \\
\text { Maximization }\end{array}$ & $\begin{array}{l}\text { Managers hold few } \\
\text { options/many shares }\end{array}$ \\
\hline $\begin{array}{l}\text { Stakeholder Risk } \\
\text { Aversion }\end{array}$ & Creditors/warranties \\
\hline
\end{tabular}

Within the domain of ERM, supply chain risk management seeks to identify potential business interruptions and prevent the occurrence and/or effectively mitigate the consequences of such events. However, absent sufficient business analytics and a comprehensive cost-benefit analysis, it can be challenging to demonstrate the value of supply chain risk management. A business case showing significant upfront capital investment needed to mitigate highly unlikely events is fundamentally more challenging than getting support for a business opportunity that has an immediate revenue enhancement. On the contrary, fundamental financial theory as discussed above posits a clear business case for reducing earnings volatility. 
This paper illustrates why risk is costly to firms and how hedging can increase shareholder value through tax savings. The simulation model incorporates three important concepts: 1) tax nonlinearity, 2) Monte Carlo loss distributions for multiple tollers, and 3) optimal insurance deductible and coverage limits. Although the concepts are fundamental in nature, integration of the three is novel and to the author's knowledge an applied simulation of this type does not exist in the literature. It is the author's intent to provide an applied simulation framework that can be used to investigate opportunities to reduce risk and increase value.

\section{LITERATURE REVIEW}

Much has been published in the open literature and peer-reviewed journals regarding risk management and more specifically managing risks related to supply chains. Depending on the capability and culture of organizations, methods to characterize risk can vary from qualitative screening tools to more quantitative risk analytical techniques. Perhaps understanding the benefits and insights from an applied perspective, organizations will begin to adopt stochastic simulation methods more broadly.

Fundamental theory of corporate risk and the role of financial hedging in the management of firms has been described in landmark papers by Mehr and Hedges (1963), Black and Scholes (1973), Cummins (1976), Mayers and Smith (1982), and Doherty (1985). The basis for the concepts related to risk reduction and convexity of the tax code are described by Smith and Stulz (1984) and Scholes, Wilson, and Wolfson (1990). A comprehensive review of integrated risk management which elucidates the concepts of these papers with practical examples was published by Doherty (2000) and is a useful resource for any practitioner. The advantages of managing risk by reduced earnings volatility and the effect of the tax shield is clearly explained.

The Handbook of Integrated Risk Management in Global Supply Chains (Kouvelis et al. 2012) is a compilation of articles related to integrated risk management, supply chain finance, operational risk management strategies, and industrial applications. The concept of flexible manufacturing and the effect of mitigating supply chain risk are discussed by Tang and Tomlin (2007) based on prior research. Furthermore, Dong and Tomlin (2012) provide a comprehensive review of operations research and insurance literature while addressing the gap that exists with respect to business interruption insurance and inventory trade-offs for mitigating supply chain risk. Their model, which addresses the interplay between inventory and business interruption insurance, considers the additional costs associated with external financing and/or the underinvestment problem. In their research, only internal manufacturing plant operations are considered, whereas upstream suppliers and CBI insurance is a subject for future research.

\section{BACKGROUND}

Firms usually rely on the expertise of insurance companies and brokers to analyze loss distributions and determine policy premiums based on coverage limits chosen by the firm. This may be satisfactory for mature or commodity businesses with few growth prospects. However, firms with many growth prospects or emerging technologies benefit from internal expertise to analyze acquisitions or an expanded supplier network. For instance, an increase in the number and size of third-party contract manufacturers exposes the firm to additional supply chain related risks. Network optimization tools are available to determine optimal flexible capacity arrangements but less is available in the literature to determine an optimal insurance policy given these inputs. 
The concept for this simulation model was to understand the implications of utilizing tollers to produce finished goods and the impact on profitability given tax nonlinearities and insurance policy decisions. For instance, consider a supply chain network as shown in Figure 2 consisting of manufacturing assets that produce proprietary intermediate formulations which are sent to tollers for final processing. The firm may choose to contract certain production steps (e.g., formulation, fill, packaging, etc.) to tollers or perhaps the entire process for mature or off-patent formulations. In order to mitigate the risk of a disruption at the tollers and the impact to profitability, firms may elect to purchase CBI insurance. CBI insurance provides indemnity to compensate for losses incurred due to interruption or stoppage of one or several suppliers. Companies that regularly or periodically contract operations to tollers expose earnings to the riskiness of the supplier network. As tolling facilities are added or individual tollers increase production capacity, the possibility of a disruption increases commensurately. This increased risk exposure should be incorporated into the decision-making process for optimal insurance coverage.

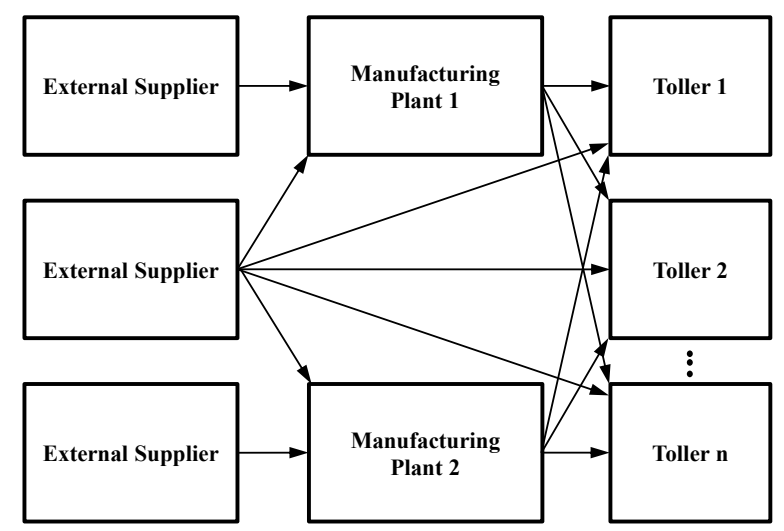

Figure 2: Diagram of a Supply Chain Network for Multiple Tollers

\section{SIMULATION APPROACH}

The model is based on a Monte Carlo simulation performed in a Microsoft Excel environment using the Palisade@Risk version6.1.2 add-in. @Risk offers an extensive set of functions to perform loss distribution fitting, simulation, and optimization. The simulation is based on a "sum of a random number of random variables" method as discussed by Vose (2008). The individual tollers experience a random number of loss events given by the frequency distribution and each loss event is contains a random number of possible business interruption costs which is represented by the severity distribution. The combination of these two random processes is simulated by sampling a discrete frequency distribution, then each of the $\mathrm{n}$ discrete events is sampled from a continuous loss distribution. The samples from the continuous loss distribution are aggregated for the $\mathrm{n}$ number of discrete events. For instance, in a year where the total number, $\mathrm{n}$, loss events from the discrete distribution equals 10 and each event sampled from a continuous distribution ranges between $\$ 1$ million $(\$ M M)$ and $\$ 10 \mathrm{MM}$, the aggregate value for the entire year would range between $\$ 10 \mathrm{MM}$ and $\$ 100 \mathrm{MM}$. This simulation evaluates the individual losses to determine if they are within the limits of the insurance policy and the aggregate total loss relative to the earnings and tax shield of the firm on an annual basis.

In practice, these distributions would be developed by collecting loss data (i.e., number of loss events and cost of each event) for each facility and fitting them with the Distribution Fit function in @ Risk. However, for this model distributions were assumed to follow Poisson and Lognormal distributions for 
frequency and severity, respectively. The model can be easily adapted to incorporate other distribution types or more complex combinations (e.g., spliced) of severity distributions in order to more accurately represent the facility loss profile. The following input variables are specified in the model:

1. Number of tollers (n)

2. Types of discrete frequency distribution

3. Average of frequency distributions

4. Types of continuous severity distribution

5. Average of severity distributions

6. Standard deviation(s) of the severity distribution

7. Deductible (D)

8. Upper coverage limit (P)

9. Premium loading (PL)

10. Gross earnings before taxes $(\mathrm{E})$

11. Marginal tax rate (TR)

12. Tax shield (TS)

\section{$\underline{\text { Policy Layers }}$}

Insurance policies assign different layers to different parties. In this model, the firm would be responsible for losses up to the deductible and any losses that exceed the residual point. The insurance company is responsible for losses (minus the deductible) that exceed the deductible and limited by the residual amount (i.e., upper coverage limit). The points at which the layers connect are referred to as attachment points. Thus, the policy deductible and residual amounts would be the attachment points for the three layers. The model determines from the simulation which layer of the insurance policy the loss falls within and assigns the loss to the respective party. Thus, each layer has a resulting distribution.

For all loss events from tollers, $\mathrm{L}_{\mathrm{ij}}$, the loss to the firm and the insurer is determined by the following equations:

Layer 1: Deductible (Firm bears risk)

$$
\begin{gathered}
L_{D}=L_{i j} \text { if } L_{i j} \leq D \\
L_{D}=D \text { if } L_{i j}>D
\end{gathered}
$$

Layer 2: Primary (Insurer bears risk)

$$
\begin{gathered}
L_{P}=0 \text { if } L_{i j} \leq D ; \\
L_{P}=L_{i j}-D \text { if } D<L_{i j}<P ; \\
L_{P}=P \text { if } L_{i j} \geq P
\end{gathered}
$$

Layer 3: Residual (Firm bears risk)

$$
\begin{gathered}
L_{R}=0 \text { if } L_{i j} \leq P \\
L_{R}=L_{i j}-P \text { if } L_{i j}>P
\end{gathered}
$$


For each of the toller facilities, a random number of losses, $\mathrm{L}_{\mathrm{ij}}$, are generated by each iteration of the simulation and the aggregate total of the losses is $\mathrm{L}_{\mathrm{T}}$ :

$$
L_{T}=L_{D}+L_{P}+L_{R}=\sum_{j}^{m} \sum_{i}^{n} L_{i j}
$$

where $\mathrm{m}$ is the random number of Poisson events and $\mathrm{n}$ is the toller.

The total loss incurred by the firm is then given by:

$$
L_{F}=L_{D}+L_{R}=L_{T}-L_{P}
$$

\section{Financial Functions}

Since the risk to the insurer is bounded between the deductible and the residual limit, the premium paid by the firm, $\mathrm{P}_{\mathrm{P}}$, to the insurer is given by:

$$
P_{P}=L_{P} * P L
$$

where PL is the premium loading.

Thus, the cost of risk to the firm, $C$, would include the total loss, $\mathrm{L}_{\mathrm{F}}$, and the premium paid to the insurer:

$$
C=L_{F}+P_{P}
$$

Pre-tax earnings (PTE) are defined as gross earnings, E, minus the cost of risk:

$$
P T E=E-C
$$

Given that earnings are not taxed below the tax shield and taxed at the marginal rate above, after-tax earnings (ATE) are defined as:

$$
\begin{gathered}
A T E=P T E \text { if } P T E \leq T S \\
A T E=P T E-\max \{T R *(P T E-T S)\} \text { if } P T E>T S
\end{gathered}
$$

\section{RESULTS}

For purposes of illustration, the simulation is generalized to a limited number of tollers and specific frequency and severity distributions. Although the inputs are hypothetical, the simulation methodology provides a basis for more complicated scenarios. The number of tollers was limited to three with Poisson frequency distributions (mean $=10$ ) and Lognormal severity distributions (mean $=10$, standard deviation $=10$ ). However, the model handles various discrete and continuous distributions as inputs.

Table 2 shows a sample from the simulation for three tollers that each observe an average of ten Poisson events per year where each event samples from a lognormal distribution with an average of $\$ 10 \mathrm{MM}$ and a standard deviation of \$10MM. For this sample, the tollers observe 16, 7, and 3 Poisson events which aggregate to $\$ 242.9 \mathrm{MM}$ is insurable losses. 
Table 2: Example of Simulation Output for the Number of Losses and Amount from the PoissonLognormal Processes.

\begin{tabular}{|c|c|c|c|}
\hline Toller & 1 & 2 & 3 \\
\hline Frequency & \multicolumn{3}{|c|}{ Poisson } \\
\hline Mean & 10 & 10 & 10 \\
\hline Severity & \multicolumn{3}{|c|}{ Lognormal } \\
\hline Mean & 10 & 10 & 10 \\
\hline S.D. & 10 & 10 & 10 \\
\hline \# of Loss Events & \multicolumn{3}{|c|}{ Loss Amount, \$MM } \\
\hline 1 & 3.7 & 5.4 & 6.9 \\
\hline 2 & 10.5 & 3.7 & 11.3 \\
\hline 3 & 8.4 & 3.4 & 5.1 \\
\hline 4 & 47.9 & 4.4 & 17.1 \\
\hline 5 & 2.7 & 11.5 & 8.1 \\
\hline 6 & 5.8 & 3.6 & \\
\hline 7 & 1.3 & 28.4 & \\
\hline 8 & 4.9 & & \\
\hline 9 & 2.0 & & \\
\hline 10 & 1.9 & & \\
\hline 11 & 4.2 & & \\
\hline 12 & 8.2 & & \\
\hline 13 & 1.6 & & \\
\hline 14 & 23.8 & & \\
\hline 15 & 0.9 & & \\
\hline 16 & 6.0 & & \\
\hline Total Number & & 28 & \\
\hline Total Amount & & 242.9 & \\
\hline
\end{tabular}

Financial variables explored in this simulation were the ratio of tax shields-to-earnings ( 0 to 1$)$ and the premium loading ( 0.1 to 0.2$)$. As tax shields decrease relative to earnings, more of the earnings are taxed at the marginal rate. Conversely, as the tax shield increases, less earnings are taxed at the marginal rate. As a premium loading is applied to the actuarial fair price, this has an obvious cost increase and reduction to final earnings. However, it is interesting to observe the impact on the advantage gained from the tax shield which includes depreciation of the firm's assets.

The expected value of the aggregate loss distributions (sum of Poisson event and Lognormal severity distributions) was approximately $\$ 300 \mathrm{MM}$ with a standard deviation of $\$ 80 \mathrm{MM}$. The earnings before subtracting losses and marginal tax rate were deterministic variables specified as $\$ 500 \mathrm{MM}$ and 0.34 , respectively, for all simulations.

\section{DISCUSSION}

Three cases were considered in the simulation model to understand the impact of the tax shield-toearnings ratio, premium loading, and the insurance policy deductible. Policies with no deductible would transfer all of the risk from the firm to the insurer. The risk to the firm is eliminated by reducing the standard deviation of ATE to \$0MM (left side of Figure 3). Alternatively, when the firm self-insurers by increasing the deductible, the standard deviation of ATE increases from left-to-right on the respective curves. The extreme scenario is when the firm fully self-insures and the standard deviation of ATE is maximized (right side of Figure 3). The optimal deductible is determined to be the location where risk, as 
measured by standard deviation of ATE, is a minimum and ATE is a maximum. The following three cases illustrate the results of the simulation.

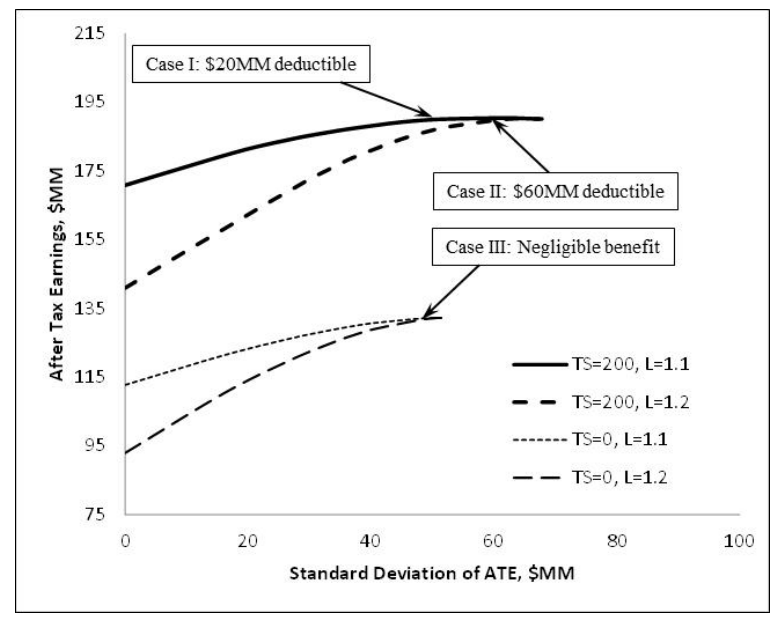

Figure 3. Effect of Insurance on Riskiness of Earnings.

\subsection{Case I}

The base case was to consider a firm with a tax shield of $\$ 200 \mathrm{MM}$ and a premium loading of $10 \%$ (i.e., insurance premium paid is $110 \%$ of the expected loss). The ratio of the tax shield to earnings after losses is approximately equal to 1 for this case. In this scenario, the firm completely self-insures the entire loss distribution. This is represented by the solid line ( $\mathrm{TS}=200, \mathrm{~L}=1.1$ ). If the firm self-insures, which is to say the firm does not purchase insurance, then risk as measured by standard deviation of the loss distribution is $\$ 67.8 \mathrm{MM}$ and after-tax earnings are $\$ 190 \mathrm{MM}$ (right side of curve). If the firm fully insures up to $\$ 500 \mathrm{MM}$ for individual losses, then risk is $\$ 0$ and earnings after premium payments are $\$ 171 \mathrm{MM}$ (left side of curve). Typically, firms finance internally predictable losses which fall below the deductible. Thus, it is interesting to explore how increasing the deductible from $\$ 0$ impacts earnings. In fact, as the deductible is increased it reaches a point of diminishing marginal returns. At a deductible of $\$ 20 \mathrm{MM}$, the after-tax earnings are $\$ 190 \mathrm{MM}$ with a standard deviation of $\$ 50 \mathrm{MM}$. By insuring the loss distribution at a deductible of $\$ 20 \mathrm{MM}$ the riskiness of earnings is reduced from $\$ 67.8 \mathrm{MM}$ to $\$ 50 \mathrm{MM}$ at equivalent earnings. Essentially, the premium paid to the insurer which reduces earnings volatility is exactly off-set by the tax savings.

\subsection{Case II}

This case explores the effect of a higher premium loading (20\%) and the same tax shield as in Case I. Obviously, given a higher premium, the amount of risk that can be reduced is significantly lower at equivalent earnings. The model indicates that a deductible of $\$ 60 \mathrm{MM}$ will reduce riskiness of earnings from $\$ 67.8 \mathrm{MM}$ to $\$ 62 \mathrm{MM}$. Thus, even as the premium increases there is still a non-negligible reduction in the riskiness of earnings.

\subsection{Case III}

The previous two cases explored the situation where the ratio of the tax shield-to-earnings was approximately 1 . Consequently, this is the most favorable scenario for taking advantage of the tax 
nonlinearity. However, in practice earnings may be significantly greater than the tax shield or equipment may be fully depreciated yielding a negligible depreciation allowance. Thus, it is prudent to consider the extreme case where the tax shield was zero.

Figure 3 indicates that the slope of the risk-earnings function is steeper and there is essentially no tax benefit to hedging the earnings. This reflects the fact that earnings are taxed at the marginal rate (0.34) as expected from a linear function starting at the origin. The results are consistent for the $10 \%$ and $20 \%$ premium loadings.

One of the challenges with the model was the computational expense due to the sum of a random number of random variables approach. This method is required in order to observe the individual loss amounts for each Poisson event. For long-tail distributions (e.g., Pareto), the simulations would require significantly more computation time. "Compound" functions (RiskCompound) exist in the software that perform the aggregation with the insurance parameters (deductible, residual limit) but the individual events are not observable and it may not be appropriate to model a complex network of tollers with separate insurance policies.

\section{FUTURE WORK}

The results reported by this model were simplified to illustrate the fundamental implications of the tax nonlinearities on earnings. More complex scenarios can be envisioned that represent actual operating firms.

Some improvements to the model to better align theory and practice would consider the following:

- Incorporate actual financial performance indicators of the firm.

- Explore the effect of increasing the number of tollers, total loss, and alternate loss distribution types (e.g., Pareto).

- Incorporate other sources of earnings variability from the manufacturing assets, such as, interest rate fluctuations for international operations.

- Perform additional simulations to understand the trade-off between the deductible and upper coverage limit.

- Consider the interplay between flexible contract manufacturing capacity (e.g., dual sourcing) and CBI insurance.

\section{CONCLUSION}

It is broadly published in the literature that risk management creates shareholder value by reducing expected bankruptcy costs, reducing expected payments to stakeholders, and reducing expected tax payments. This simulation model is an initial step towards quantifying the benefit of reduced riskiness of earnings as a result of the tax shield nonlinearity. Although generalized, the model can be extended to represent more complex supply chains. For a tax shield-to-earnings ratio near 1, it is feasible that equivalent after-tax earnings can be obtained at reduced risk. In practice, this will depend on the premium loading that the insurer charges and the loss distributions of the firm. In order to maximize shareholder value, it is beneficial to explore the sources of earnings volatility and insurable losses to manage supply chain risk. 


\section{DISCLAIMER}

The information and opinions presented herein are not intended as tax advice. The readers and/or users of the information presented in this paper should consult with their own tax advisors before taking any action based on the intended tax result.

\section{REFERENCES}

Black, F. and M. Scholes. 1973. "The Pricing of Options and Corporate Liabilities." Journal of Political Economy 81:637-54.

Cummins, J.D. 1976. "Risk Management and the Theory of the Firm." Journal of Risk and Insurance XLIII:587-609.

Doherty, N.A. 1985. Corporate Risk Management: A Financial Exposition. New York: McGraw-Hill, Inc.

Doherty, N.A. 2000. Integrated Risk Management: Techniques and Strategies for Reducing Risk. New York: McGraw-Hill, Inc.

Dong, L., and B. Tomlin. 2012. "Managing Disruption Risk: Interplay Between Operations and Insurance." Management Science 58.10:1898-1915.

Harrington, S.E., Niehaus, G., and K.J. Risko. 2002. "Enterprise Risk Management: The Case of United Grain Growers." Journal of Applied Corporate Finance 14.4:71-81.

Kouvelis, P., Dong, L., Boyabatli, O., and R. Li. 2012. Handbook of Integrated Risk Management in Global Supply Chains. New Jersey: John Wiley \& Sons, Inc.

Mayers, D., and C.W. Smith Jr. 1982. "On the Corporate Demand for Insurance." Journal of Business 55:281-96.

Mehr, R.I., and B.A. Hedges. 1963. Risk Management in the Business Enterprise. Homewood, Illinois: R.D. Irwin.

Miller, M.H., and F. Modigliani. 1958. "The Cost of Capital, Corporation Finance and the Theory of Investment." The American Economic Review 48.3:261-297.

Scholes, M., Wilson, G.P., and M.A. Wolfson. 1990. "Tax Planning, Regulatory Capital Planning and Financial Reporting Strategy for Commercial Banks.” The Review of Financial Studies 3.4:625-650.

Smith, C.W. Jr., and R.M. Stulz. 1985. "The Determinants of Firms' Hedging Policies.” Journal of Financial and Quantitative Analysis 28:391-405.

Stulz, R.M. 1996. "Rethinking Risk Management." Journal of Applied Corporate Finance 9.3:8-24.

Tang, C., and B. Tomlin. 2008. "The Power of Flexibility for Mitigating Supply Chain Risks." Int. J. Production Economics 116: 12-27.

Vose, D. 2008. Risk Analysis: A Quantitative Guide. England: John Wiley \& Sons, Ltd. 


\section{AUTHOR BIOGRAPHY}

ELLIOT M. WOLF is the Production and Supply Risk Management Lead for North America at Syngenta Crop Protection in Greensboro, North Carolina. He has worked for the past several years in risk engineering, loss prevention, loss forecasting, and stochastic simulation of supply chain systems. Previously, he worked in a research and development capacity with NOVA Chemicals Inc. and in a manufacturing technical role with DuPont Performance Elastomers. He holds a B.S. in Chemical Engineering from the University of Pittsburgh, a Master of Chemical Engineering from the University of Delaware, and a Master of Business Administration from the Tepper School of Business at Carnegie Mellon University. His e-mail address is elliot.wolf@syngenta.com. 